\section{Hungary as neurosciences audit}

SIR-The meeting of the International Brain Research Organization (IBRO) the second World Congress of Neuroscience, held in Budapest from 16 to 21 August - with some 3,000 participants, makes an interesting testing ground for international comparisons on relative scientific standing. I have therefore analysed the oral and poster presentations listed in the conference programme by geography of origin. In the recent past British contributions to neuroscience have been pre-eminent, and one might have expected a high British profile at the meeting. Because the meeting was held in Hungary, it could be presumed that access was relatively easier to Europeans, East and West, and somewhat less to participants from other continents, than would have been the case with another venue

The oral presentations were all invited, and therefore indicate the 'visibility' both of subject areas and the leading researchers within them. Of 612 listed papers, only 59 - just under 10 per cent - were from UK laboratories. Thirtyseven per cent were from East or West Europe, 37 per cent from the United States, a miserable 3 per cent from the Soviet Union and 13 per cent from the rest of the world, predominantly Japan, Canada, Australia and Israel.

Poster presentations were self-contributed, and as far as I know all those submitted were accepted. In one full day's set of 490 posters, just under 20 per cent of the entire meeting, only 23 , or fewer than 5 per cent, were from UK laboratories. Thirty-one per cent were from East and 34 per cent from West Europe, 13 per cent were from the United States, fewer than 5 per cent from the Soviet Union, and the rest of the world contributed 12 per cent.

The first conclusion to be drawn is that the high visibility of contributions from US laboratories, leading to their domination of the oral sessions, can only enhance the well-known Matthew effect by which to him that hath more shall be given.

Second, the continuing prestige of senior UK scientists ensured them a significant presence among the oral presentations, but the weakness of the underlying position of UK neuroscience is shown by the small number of poster contributions. The more junior British scientists either had little to say or, more likely, were simply unable to raise the funds to attend. These two observations support the view that if European science is to increase its own visibility, it must reinforce its own cooperative mechanisms rather than stand so passively in awe of US achievements.

Third, the tiny representation of Soviet scientists even at an Eastern European meeting of a Unesco-sponsored organiza- tion to which the Soviet Union is affiliated, and despite the distinguished Soviet neuroscientific tradition, may say something about how far glasnost still has to go.

Fourth, it is a mockery of the concept of internationalism when a 'world' meeting boasts no contributions from Africa and only a handful from India, China and Latin America. IBRO's world remains overwhelmingly white.

Fifth, the gendered pronoun I used to define the Matthew effect was no slip of the pen. I estimate that $20-30$ per cent of those attending the meeting were women. A significant number of the posters had women authors and women presenters. But women speakers in the oral sessions were conspicuous by their absence. Given the chance to choose speakers for these sessions, it seems the predominantly masculine group of organizers and chairs could see only men.

The pattern of this meeting is likely to be mirrored in the thousands of other international meetings held each year. And it is precisely because of this - and also because in this case the organizing body, through its ultimate links with the United Nations, has legitimate claims to universalism - that the experience is worth pondering, rather than being regarded simply as part of the natural order of the scientific world. At the least, positive efforts, nationally and internationally, are needed to help redress the imbalances that this simple numerical exercise reveals.

Brain Research Group, Steven Rose

Open University,

Milton Keynes $M K 76 A A, U K$

\section{Aleksandrov's visit}

SIR-Vera Rich (Nature 327, 544; 1987) writes that SCOPE may have put restrictions on Vladimir Aleksandrov during his US visit in January 1985 . Not so. SCOPEENUWAR has given every opportunity for speedy communication of new information, incurring criticism for not going to recognized journals with standard refereeing. I know Aleksandrov was not allowed direct access to Cray computers during his US visit.

Aleksandrov visited Japan in February 1985 for the SCOPE-ENUWAR workshop and said he was able freely to discuss climate modelling during his US visit. In Japan he openly met scientists from Livermore, Colorado State University, NCAR Boulder, NASA-Ames, France, West Germany, Australia, Sweden and Japan. He talked to me about personal problems of his wife's health and up to the time of his disappearance was sending medical reports for study in England with a view to arranging treatment.
Aleksandrov is still missed by his collaborators in ENUWAR, and at their Bangkok meeting in February they renewed the consensus on the predictions of climate change made in the SCOPE report which acknowledged the insight given by the limited one-dimensional model of Aleksandrov and Stenchikov.

FREDERICK WARNER (Chairman, SCOPE-ENUWAR Steering Committee)

Department of Chemistry,

University of Essex, Colchester CO4 $3 S Q, U K$

VERA RICH REPLIES - The suggestion that Aleksandrov may have been restricted during his final visit to the Livermore Laboratory was originally made from the Soviet side, and confirmed in telephone conversations by his US hosts, who clearly felt awkward about the situation. I made no suggestions about the propricty or otherwise of such surveillance - which, according to Aleksandrov's hosts, was considerably less than that which I would accept as normal in working in a socialist-bloc country. [

\section{Argentine trials}

SIR-K.S. Jayaraman (Nature 328, 287; 1987), refers to a statement by $\mathrm{Dr} S$. Ramachandran that "Argentine controversy (over rabies vaccine) arose because Wistar failed to inform the government".

The published facts (Nature 326, 636; 1987) reveal that: (1)The trial in Argentina was carried out by the Pan American Health Organization not by the Wistar Institute. And (2) the "controversy" arose because an Argentinian scientist decided to play politics instead of considering the trial as an important step in evaluating a vaccine which may represent the best way of preventing rabies infection.

Wistar Institute,

HILARY KOPROWSKI 36th Street at Spruce, Philadelphia, Pennsylvania 19104-4268, USA

\section{Human embryo}

SiR-Your suggestion (Nature 327, 87; 1987) to ban the unnecessary word "preembryo" (an embryo before implantation) is well taken. At the Carnegie Collection, in human embryology, the term embryo is used for the "human offspring in first eight weeks" (Concise Oxford Dictionary). Hence prenatal life is subdivided into merely two periods: embryonic and fetal. Terms we have discarded for the human embryo include ovum (used incorrectly for everything from unfertilized oocyte to three-week embryo), 'egg' (best reserved for a nutritive object sometimes seen on the breakfast table), and blastula, blastocoel, blastopore, gastrula, branchial, all of which are inappropriate.

R. O'RAHILLY

Carnegie Laboratories of Embryology,

California Primate Research Center,

Davis, California 95616, USA 